\title{
Self-administered interventions for anogenital warts in immunocompetent patients: a systematic review and meta-analysis
}

\author{
Ricardo Niklas Werner, Lukas Westfechtel, Corinna Dressler, Alexander Nast
}

- Additional material is

published online only. To view please visit the journal online (http://dx.doi.org/10.1136/ sextrans-2016-052768).

Division of Evidencebased Medicine, Klinik für Dermatologie, Venerologie und Allergologie, CharitéUniversitätsmedizin Berlin, Berlin, Germany

\section{Correspondence to} Dr Ricardo N Werner, Division of Evidence based Medicine (dEBM), Klinik für Dermatologie, Venerologie und Allergologie, Charité-Universitätsmedizin Berlin, Charitéplatz 1, Berlin 10117, Germany; ricardo. werner@charite.de

RNW and LW contributed equally to this work

Received 22 June 2016 Revised 27 September 2016 Accepted 10 October 2016 Published Online First 1 November 2016

CrossMark

\footnotetext{
To cite: Werner RN, Westfechtel L, Dressler C, et al. Sex Transm Infect 2017;93:155-161.
}

\section{ABSTRACT \\ Background Anogenital warts (AGWs, condylomata} acuminata) are among the most common STIs and may severely impact quality of life (QoL). Available treatment options are characterised by a high proportion of nonresponders and recurrences.

Objective To systematically review and meta-analyse the available evidence from randomised controlled trials (RCTs) on topical treatments for AGWs considering short-term and long-term efficacy, effects on QoL and adverse events (AE).

Methods A comprehensive literature search was performed in Cochrane Central Register of Controlled Trials, Embase and MEDLINE. Included studies were evaluated with the Cochrane Collaboration's risk of bias tool. The confidence in the pooled effect estimates was evaluated according to the Grading of Recommendations Assessment, Development and Evaluation (GRADE) approach and categorised as 'very low', 'low', 'moderate' or 'high'.

Results Eighteen RCTs met the inclusion criteria. Regarding complete clearance (CC), imiquimod 3.75\% and $5 \%$ cream, podophyllotoxin $0.5 \%$ solution and gel and polyphenon E $10 \%$ and $15 \%$ ointment were superior to placebo. Although more local AE and pain occurred in the actively treated groups, differences regarding dropouts due to $A E$ were not statistically significant. For podophyllotoxin $0.15 \%$ cream, no placebo-controlled trials were available; however, in an active-controlled trial, it was inferior to podophyllotoxin $0.5 \%$ solution with respect to CC. No significant differences were detected between imiquimod $5 \%$ cream and podophyllotoxin $0.5 \%$ solution and between polyphenon $\mathrm{E} 10 \%$ and $15 \%$ ointment. No data on the influence on health-related QoL were available.

Conclusion Our confidence in the pooled estimates (GRADE quality of the evidence) ranged from very low to high. Apart from the given results, other aspects such as availability, costs or patient preference have to be considered when making a treatment choice. Due to the limited number of direct comparisons, conclusions on the relative efficacy of the different treatment options are restricted.

\section{INTRODUCTION}

Anogenital warts (AGWs, condylomata acuminata) are the manifestation of a usually sexually transmitted infection (STI) with particular types of the human papillomavirus (HPV). HPV DNA is detected in around 90\% of AGWs, with type 6 and 11 accounting for $95 \%{ }^{\text {w1 }}$ AGWs are among the most common STI diagnoses in several European countries, accounting for up to $41.2 \%$ of all STI notifications. The highest incidence rates have been reported in young females (aged 16-19 years) and males (aged 20-24 years). ${ }^{\text {w2 }}$ As shown in the context of different national healthcare systems, the socioeconomic burden of AGWs is considerable. ${ }^{\text {w3- }}$ w7

Although not associated with a significant mortality, AGWs may cause severe distress and discomfort in affected patients and consequently a significant loss in quality of life (QoL) as compared with the general population. ${ }^{\text {w8-w13 }}$ Studies identified psychosocial distress, anxiety, impact on sexual life, physical symptoms, painful treatments and high rates of recurrence as major factors reducing the QoL in patients with AGWs or cytological abnormalities. ${ }^{\text {w14-w18 }}$ Patient preferences with respect to treatment options have not been well studied. One study, based on structured interviews with 166 patients with genital warts, reports that most patients would have preferred to be treated with a self-applied topical medication. ${ }^{\text {w15 }}$

Since anogenital HPV infections are highly contagious and AGWs are among the most common STIs, it is relevant to identify effective treatment strategies. Patient-reported outcomes and local adverse events (AE) are crucial aspects for the choice of a management strategy. Due to high recurrence rates of $\sim 20 \%$ to $50 \%$ (range: $6-100 \%$ ), ${ }^{\mathrm{w} 19} \mathrm{w}^{\mathrm{w} 20}$ aspects related to treatment adherence are of major importance. The aim of this systematic review was to comprehensively evaluate the available evidence from randomised controlled trials (RCTs) of patientadministered interventions licensed for the treatment of AGWs in Europe and North America.

\section{METHODS}

The systematic assessment and analysis of the included studies were based on the methodology recommended by the Cochrane Handbook for Systematic Reviews of Interventions ${ }^{\mathrm{w} 21}$ and the 'Grading of Recommendations Assessment, Development and Evaluation' (GRADE) approach. $^{\text {w22 }}$

\section{Eligibility criteria}

Studies had to report data on immunocompetent participants clinically diagnosed as having at least one AGW at baseline. Both patients with internal (anal, vaginal) and external (penile, scrotal, vulval, inguinal, perineal, perianal) lesions were considered. 
Subclinical HPV infections as well as cervical and intraurethral lesions were excluded.

Interventions included topical, self-administered treatment options licensed in North America or Europe: imiquimod $3.75 \%$ and $5 \%$ cream, podophyllotoxin $0.15 \%$ cream, $0.5 \%$ solution and $0.5 \%$ gel and polyphenon E (sinecatechins) $10 \%$ and $15 \%$ ointment. Any of the included interventions, placebo preparations, vehicle or no treatment could serve as comparator. Combinations with other treatment options were not considered.

Studies had to report at least one of the following primary outcomes: complete clearance (CC) at 2 weeks ( \pm 2 weeks) ('short-term CC') or at 16 weeks ( \pm 8 weeks) after the end of treatment (EOT) ('intermediate-term CC') or dropouts due to AE. CC was defined as the absence of any lesion (baseline and new lesions) or as the absence of baseline lesions at the time of assessment. If available, the following secondary outcomes were considered: pain (numeric scales or dichotomised outcome), local $\mathrm{AE}$ (erythema/inflammation/skin irritation, erosion/excoriation/ulceration), QoL (validated assessment tools); recurrence of lesions at 16 weeks ( \pm 8 weeks) ("intermediate-term recurrence] or at 12 months ( \pm 2 months) after EOT ('long-term recurrence') in responders who had a $\mathrm{CC}$ at EOT; and CC at 12 months after EOT ( \pm 2 months) ('long-term CC').

Study design was restricted to RCTs. Abstracts were excluded; language was restricted to English and German.

\section{Literature searches and data management}

A literature search was performed in the Cochrane Central Register of Controlled Trials, Embase and MEDLINE (for details, see online supplement).

Titles and abstracts were screened for eligibility by two investigators (RNW, LW) independently. Each title/abstract included was then independently assessed as full text by two investigators (RNW, LW). Reasons for the exclusion of studies during the fulltext evaluation were recorded.

Data were extracted by two independent investigators (RNW, LW), using standardised forms. Disagreements were resolved by discussion or by the third investigator (AN). Data items are listed in the online supplementary file. The results were assessed according to the intention to treat population; if these data were not reported, we applied a non-responder imputation for CC rates. Authors of studies were contacted if data on primary outcomes were not reported (eg, clearance rate not reported for placebo group).

Dichotomous outcomes were reported as risk ratios (RRs) ${ }^{\text {w23 }}$ and continuous outcomes as mean differences, ${ }^{\mathrm{w} 24}$ including a 95\% CI. Pooled estimates were calculated by means of Mantel-Haenszel meta-analyses, applying a random effects model (DerSimonian and Laird). ${ }^{\text {w21 }}$ The analyses were conducted using the Review Manager. ${ }^{\text {w25 }}$ Study data were not pooled in case of clinical or statistical heterogeneity, $\left(\mathrm{I}^{2}\right.$ test $\left.>60 \%\right)$.

\section{Risk of bias and overall quality of evidence}

The assessment of the quality of evidence was based on the GRADE approach ${ }^{1}$ : The 'Cochrane Collaboration's tool for assessing risk of bias in randomised trials, ${ }^{2}$ was used to assess the risk of bias at the study level. The overall confidence in the pooled estimates of effect $^{3}$ was evaluated on the outcome level, considering the risk of bias assessment, ${ }^{4}$ inconsistency, ${ }^{5}$ indirectness, ${ }^{6}$ imprecision ${ }^{7}$ and publication bias. ${ }^{8}$ The criteria for rating these items are described in the online supplement. The overall quality of the evidence was categorised as: very low, low, moderate or high.

\section{RESULTS}

The literature search yielded 665 hits. After removing duplicates, 454 publications were evaluated. During the title and abstract screening, 411 records were excluded, leaving 43 hits for the full-text evaluation. Of these, 18 were included. Figure 1 gives a visual presentation of the literature identification process (figure 1: PRISMA flow chart). Detailed reasons for the exclusion of studies in the full-text evaluation are given in the online supplement.

The 18 included studies comprised 2-3 study arms and included a total of 3319 randomised participants. Online supplementary table S1 gives an overview of the study and sample characteristics. All included studies investigated participants with external AGWs. No studies reporting data on internal AGWs were eligible. One study included patients with anal AGWs, but the vast majority of participants had external AGWs. ${ }^{9}$ No data on the influence of any of the interventions on health-related QoL were available.

Generally, risk of bias in the included trials was heterogeneous (figure 2: risk of bias summary, more detailed information: see online supplement).

For each of the comparisons listed below, detailed results are given in the online supplement, including summary of findings tables and reasons for downgrading the overall quality of the evidence.

\section{Imiquimod $3.75 \%$ cream versus placebo}

Two trials ${ }^{10}{ }^{11}$ compared imiquimod $3.75 \%$ cream with its vehicle $(\mathrm{N}=601$, study characteristics see online supplementary table S1). Imiquimod $3.75 \%$ cream was applied daily for up to 8 weeks; rest periods to manage local reactions were allowed as needed. Intermediate-term CC was higher for imiquimod (figure 3A, GRADE: HIGH quality). With respect to dropouts due to $\mathrm{AE}$, no statistically significant differences were seen (2 RCTs, RR 2.14, 95\% CI 0.36 to 12.59, GRADE: MODERATE quality). Local AE occurred at a higher frequency in participants treated with imiquimod $3.75 \%$ cream (pain: 1 RCT, RR 17.18 , 95\% CI 1.04 to 282.95 , GRADE: LOW quality; erythema/inflammation/skin irritation: 1 RCT, RR 21.30, $95 \%$ CI 1.30 to 348.79 , GRADE: MODERATE quality; erosion/excoriation/ulceration: 1 RCT, RR 13.45, 95\% CI 1.85 to 97.73 , GRADE: HIGH quality).

\section{Imiquimod 5\% cream versus placebo}

Imiquimod 5\% cream was compared with vehicle or placebo in five trials ${ }^{9}{ }^{12-15} \quad(n=571$, study characteristics see online supplementary table S1). The data reported for CC and recurrence rates solely referred to baseline lesions in two trials. ${ }^{9} 14$ Imiquimod 5\% cream was superior with respect to short-term CC (figure 3B, GRADE: LOW quality). No statistically significant differences were found regarding dropouts due to $\mathrm{AE}$ (3 RCTs, RR 4.30, 95\% CI 0.48 to 38.34, GRADE: MODERATE quality). Participants in the imiquimod 5\% cream group had higher rates of pain and local AE than placebotreated participants (pain: 1 RCT, RR 16.00, 95\% CI 3.95 to 64.82, GRADE: HIGH quality; erythema/inflammation/skin irritation: 3 RCTs, RR 2.36, 95\% CI 1.87 to 2.98, GRADE: MODERATE quality; erosion/excoriation/ulceration: 3 RCTs, RR 6.80 , 95\% CI 4.16 to 11.12, GRADE: MODERATE quality). No statistically significant differences were found for intermediate-term recurrence (3 RCTs, RR 1.44, 95\% CI 0.28 
Figure 1 PRISMA flowchart. Depicts the process of study identification.

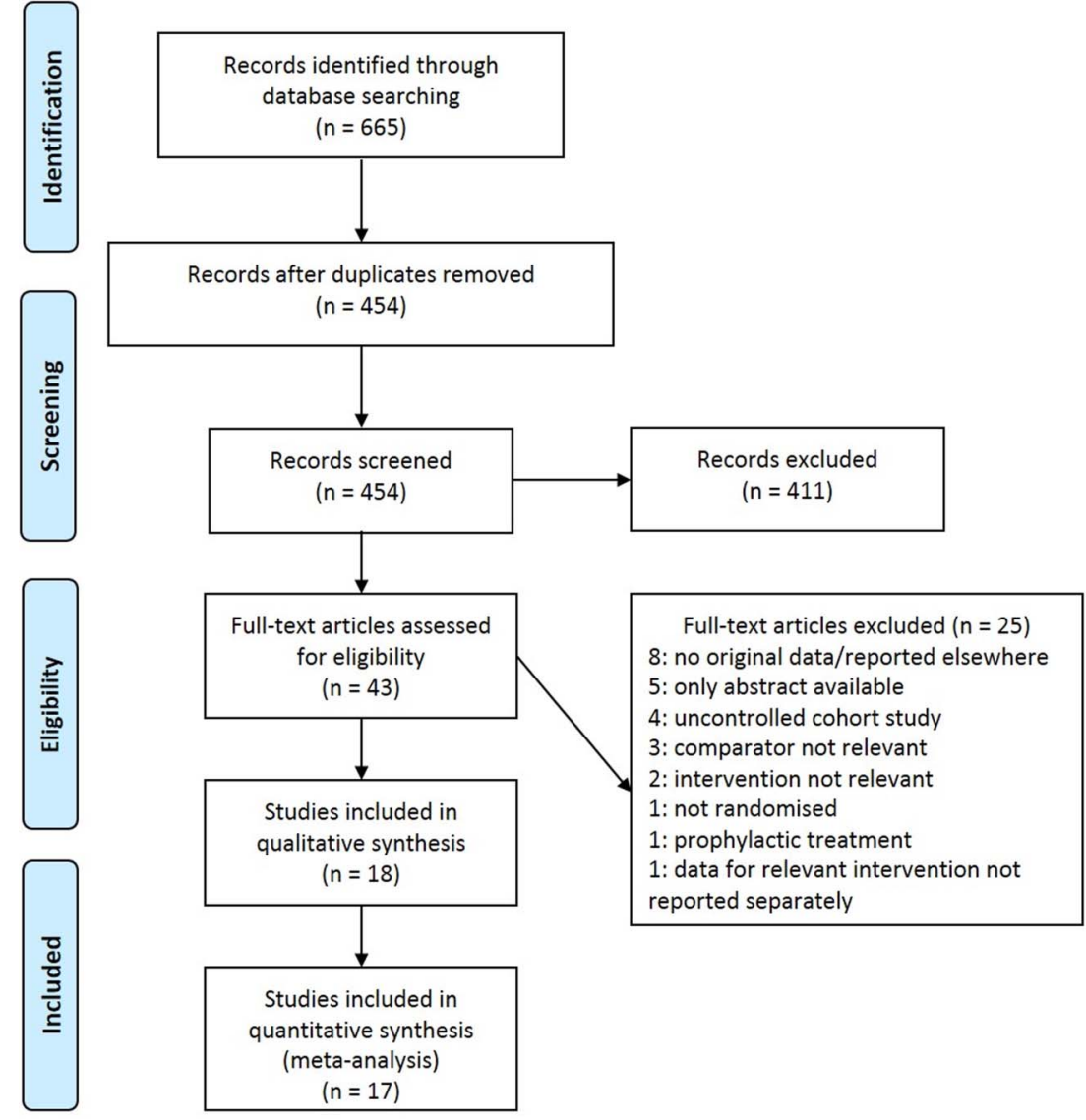

to 6.97, GRADE: LOW quality). Data on short-term CC from one trial ${ }^{15}$ were not included into the meta-analysis due to the design and unclear reporting in the study. In this study, 7/16 and $1 / 4$ participants completely cleared in the imiquimod $5 \%$ cream group and in the placebo group, respectively.

\section{Podophyllotoxin $0.5 \%$ solution versus placebo}

Podophyllotoxin $0.5 \%$ solution was compared with placebo in three studies ${ }^{16-18} \quad(\mathrm{~N}=185$, study characteristics see online supplementary table S1). Concerning short-term CC, podophyllotoxin $0.5 \%$ solution was superior to placebo (figure $3 \mathrm{C}$, GRADE: LOW quality). Referring to the reported AE, podophyllotoxin $0.5 \%$ solution was inferior to placebo (pain: 2 RCTs, RR 5.86, 95\% CI 1.01 to 33.85, GRADE: LOW quality; erythema/inflammation/skin irritation: 2 RCTs, RR 12.67, 95\% CI 4.50 to 35.64, GRADE: MODERATE quality; erosion/excoriation/ulceration: 2 RCTs, RR 17.68, 95\% CI 5.16 to 60.52 , GRADE: MODERATE quality). Two studies ${ }^{16} 17$ reported intermediate-term recurrence. In both trials, none of the participants from the placebo groups had a CC, so that the RR could not be calculated. In the verum groups, $15 / 25^{16}$ and $1 / 2^{17}$ completely cleared participants had a recurrence, respectively.

\section{Podophyllotoxin $\mathbf{0 . 5 \%}$ gel versus placebo}

For the comparison of podophyllotoxin $0.5 \%$ gel to its vehicle, one trial ${ }^{19} \quad(\mathrm{~N}=326$, study characteristics see online supplementary table S1) was identified. The rate of short-term CC was higher for podophyllotoxin gel (figure 3D, GRADE: MODERATE quality). No statistically significant differences were seen regarding dropouts due to $\mathrm{AE}$ (RR 7.36, 95\% CI 0.42 to 127.74, GRADE: VERY LOW quality). Higher rates of AE were seen for podophyllotoxin $0.5 \%$ gel (pain: RR 9.27, 95\%
CI 4.22 to 20.35, GRADE: MODERATE quality; erythema/ inflammation/skin irritation: RR 6.13, 95\% CI 3.75 to 10.50 , GRADE: MODERATE quality; erosion/excoriation/ulceration: RR 18.54, 95\% CI 6.04 to 56.92, GRADE: MODERATE quality). Intermediate-term recurrence was seen in 25/81 participants in the podophyllotoxin $0.5 \%$ gel group; these data were not reported for the placebo group.

Polyphenon E (sinecatechins) 10\% ointment versus placebo Two studies ${ }^{20} 21 \quad(\mathrm{~N}=608$, study characteristics see online supplementary table S1) were available for the comparison of polyphenon E $10 \%$ ointment to its vehicle. Short-term CC occurred with a higher frequency in the participants treated with polyphenon E 10\% ointment (figure 3E, GRADE: MODERATE quality). Dropouts due to AE were not different between the groups (2 RCTs, RR 0.52, 95\% CI 0.03 to 8.19, GRADE: MODERATE quality). Similarly, no statistically significant differences were detected with respect to intermediate-term recurrence (1 RCT, RR 1.54, 95\% CI 0.18 to 13.30 , GRADE: MODERATE quality).

Polyphenon E (sinecatechins) 15\% ointment versus placebo Polyphenon E 15\% ointment was compared with placebo in three studies ${ }^{20-22}(\mathrm{~N}=767$, study characteristics see online supplementary table S1). Polyphenon E 15\% ointment was superior to placebo regarding short-term CC (figure $3 \mathrm{~F}$, GRADE: HIGH quality). Referring to dropouts due to AE, no statistically significant differences between the groups were detected (2 RCTs, RR 3.33, 95\% CI 0.74 to 15.05, GRADE: MODERATE quality). No statistically significant differences were seen for intermediate-term recurrence (1 RCT, RR 1.38, 95\% CI 0.44 to 4.30 , GRADE: MODERATE quality). 




Figure 2 Risk of bias summary. Review authors' judgements about each risk of bias item for the included studies.

\section{Podophyllotoxin $0.5 \%$ solution versus podophyllotoxin $0.15 \%$ cream}

Three studies $^{23-25}(\mathrm{~N}=417$, study characteristics see online supplementary table $\mathrm{S} 1$ ) were available to compare different podophyllotoxin preparations $(0.5 \%$ solution vs $0.15 \%$ cream).
Regarding short-term CC, podophyllotoxin $0.5 \%$ solution was superior to $0.15 \%$ cream (figure 4A, GRADE: LOW quality). No statistically significant differences were seen for intermediate-term CC (1 RCT, RR 1.22, 95\% CI 0.82 to 1.81 , GRADE: LOW quality), for erythema/inflammation/skin irritation (1 RCT, RR 1.00, 95\% CI 0.70 to 1.43, GRADE: LOW quality) and for intermediate-term recurrence (3 RCTs, RR $0.91,95 \%$ CI 0.57 to 1.45 , GRADE: LOW quality). For the outcome of erosion/excoriation/ulceration, a meta-analysis was not performed due to statistical heterogeneity of the results $\left(\mathrm{I}^{2}=75 \%\right)$. The $\mathrm{RR}$ in the two single studies were $0.76(95 \% \mathrm{CI}$ 0.53 to 1.13$)^{23}$ and 1.55 (95\% CI 0.83 to 2.87 ), ${ }^{24}$ showing no statistically significant between-group differences in both trials.

Imiquimod $5 \%$ cream versus podophyllotoxin $0.5 \%$ solution One study ${ }^{26} \quad(\mathrm{~N}=51$, study characteristics see online supplementary table S1) was available for the comparison of imiquimod $5 \%$ cream and podophyllotoxin $0.5 \%$ solution. For none of the three reported outcomes, a statistically significant difference between the interventions was detected (short-term CC: figure 4B, GRADE: LOW quality; erythema/inflammation/ skin irritation: RR $1.17,95 \%$ CI 0.80 to 1.73 , GRADE: LOW quality; erosion/excoriation/ulceration: RR 1.48, 95\% CI 0.86 to 2.55 , GRADE: LOW quality).

\section{Polyphenon E (sinecatechins) $10 \%$ versus $15 \%$ ointment}

For the comparison of polyphenon $\mathrm{E}$ ointment at different concentrations $(10 \%$ and $15 \%)$, two studies ${ }^{20} 21$ ( $\mathrm{N}=798$, study characteristics see online supplementary table $\mathrm{S} 1$ ) were available. No statistically significant differences were detected for any of the assessed outcomes (short-term-CC: figure 4C, GRADE: HIGH quality; dropouts due to AE: 2 RCTs, RR 4.87, 95\% CI 0.84 to 28.31, GRADE: MODERATE quality; intermediateterm recurrence: 1 RCT, RR 1.46, 95\% CI 0.42 to 5.00, GRADE: LOW quality).

\section{Additional analyses}

Due to the small number of trials included for each of the interventions, no further analyses such as subgroup analyses or funnel plots for the detection of publication bias could be performed.

\section{DISCUSSION}

All interventions included were superior to placebo regarding the main efficacy outcomes of short- and intermediate-term CC. In those comparisons that included studies assessing pain and local reactions, participants from the interventional groups had higher rates of $\mathrm{AE}$ when compared with the placebo groups. In contrast, no statistically significant differences between the interventions and placebo controls were seen with respect to dropouts due to $\mathrm{AE}$ (not assessed for podophyllotoxin $0.5 \%$ solution). This suggests that although actively treated patients had more local reactions and reported more pain, the severity of these treatment-related $\mathrm{AE}$ was acceptable for the participants.

Very few direct comparisons between interventions were found: podophyllotoxin $0.5 \%$ solution was superior to $0.15 \%$ cream regarding short-term CC, although this difference is of questionable clinical importance. No differences were seen for intermediate-term CC and for safety outcomes. For podophyllotoxin $0.5 \%$ solution versus imiquimod $5 \%$ cream and polyphenon $\mathrm{E} 10 \%$ vs $15 \%$ ointment, differences in efficacy or safety outcomes were also not seen. For polyphenon E preparations, local $\mathrm{AE}$ relevant to this systematic review were not reported. However, the comparison of polyphenon E $10 \%$ vs $15 \%$ 
A

\begin{tabular}{|c|c|c|c|c|c|c|c|c|c|}
\hline Study or Subgroup & \multicolumn{2}{|c|}{ imiquimod $3.75 \%$ cream } & \multicolumn{2}{|c|}{ placebo } & Weight & $\begin{array}{c}\text { Risk Ratio } \\
\text { M.H, Random, } 95 \% \mathrm{Cl}\end{array}$ & \multicolumn{3}{|c|}{$\begin{array}{c}\text { Risk Ratio } \\
\text { M.H, Random, } 95 \% \mathrm{Cl}\end{array}$} \\
\hline 8aker 2011 (1) & 79 & 216 & 15 & 106 & $80.2 \%$ & $2.58[1.57,4.26]$ & & & \\
\hline Rosen 2015 (2) & 34 & 183 & 4 & 96 & $19.8 \%$ & $4.46[1.63,12.20]$ & & & \\
\hline Total $(95 \% \mathrm{Cl})$ & & 399 & & 202 & $100.0 \%$ & $2.88[1.84,4.51]$ & & & \\
\hline Total events & 113 & & 19 & & & & & & \\
\hline $\begin{array}{l}\text { Heterogeneity. Tau } \\
\text { Test for overall effec }\end{array}$ & $\begin{array}{l}0.00: C h P^{2}=0 . \\
Z=4.63(P<0\end{array}$ & $=1(P=$ & $0.34): 1^{2}=$ & $=0 \%$ & & & 0.01 & $\begin{array}{c}0.1 \\
\text { Favours placebo }\end{array}$ & $\begin{array}{c}10 \\
\text { Favours imiquimod } \\
3.75 \%\end{array}$ \\
\hline
\end{tabular}

Footnotes

(1) Complete clearence at 8 weeks aner EOT

(2) Complete clearence at 8 weeks after EOT

B

Imiquimod $3.75 \%$ cream vs. placebo, intermediate-term complete clearance.

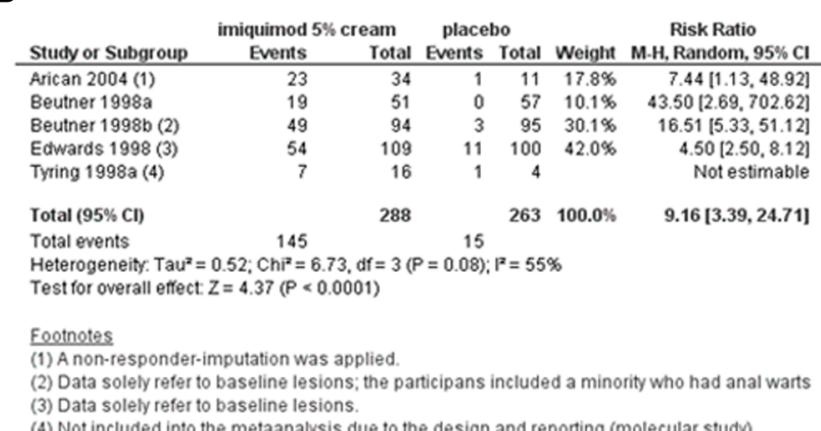

(4) Not included into the metaanalysis due to the design and reporting (molecular study).

Imiquimod 5\% cream vs. placebo, short-term complete clearance.

C

\begin{tabular}{|c|c|c|c|c|c|c|c|c|c|}
\hline Study or Subgroup & \multicolumn{2}{|c|}{ podophyllotoxin $0.5 \%$ sol. } & \multicolumn{2}{|c|}{ placebo } & Weight & $\begin{array}{c}\text { Risk Ratio } \\
\text { M.H, Random, } 95 \% \mathrm{Cl}\end{array}$ & \multicolumn{3}{|c|}{$\begin{array}{c}\text { Risk Ratio } \\
\text { M.H, Random, } 95 \% \text { Cl }\end{array}$} \\
\hline Beutner 1989 & 25 & 56 & 0 & 53 & $34.7 \%$ & $48.32[3.02,774.14]$ & & & $\Longrightarrow$ \\
\hline Karby 1990 & 2 & 19 & 0 & 19 & $30.2 \%$ & $5.00[0.26,97.70]$ & & & \\
\hline Krogh 1994 & 13 & 19 & 0 & 19 & $35.2 \%$ & $27.00[1.72,423.95]$ & & & $\longrightarrow$ \\
\hline Total $(95 \%$ Cl) & & 94 & & 91 & $100.0 \%$ & $19.86[3.88,101.65]$ & & & \\
\hline Total events & 40 & & 0 & & & & & & \\
\hline $\begin{array}{l}\text { Heterogeneity. Tauz } \\
\text { Test for overall effec }\end{array}$ & $\begin{array}{l}0.00 ; C h i^{2}=1.4 \\
Z=3.59(P=0 .\end{array}$ & $2(P=0$ & (50): $1^{2}=$ & & & & 0.01 & $\begin{array}{c}0.1 \\
\text { Favours placebo }\end{array}$ & $\begin{array}{c}10 \\
10 \\
\text { Favours podophyllotoxin }\end{array}$ \\
\hline
\end{tabular}

Podophyllotoxin $0.5 \%$ solution vs. placebo, short-term complete clearance.

D

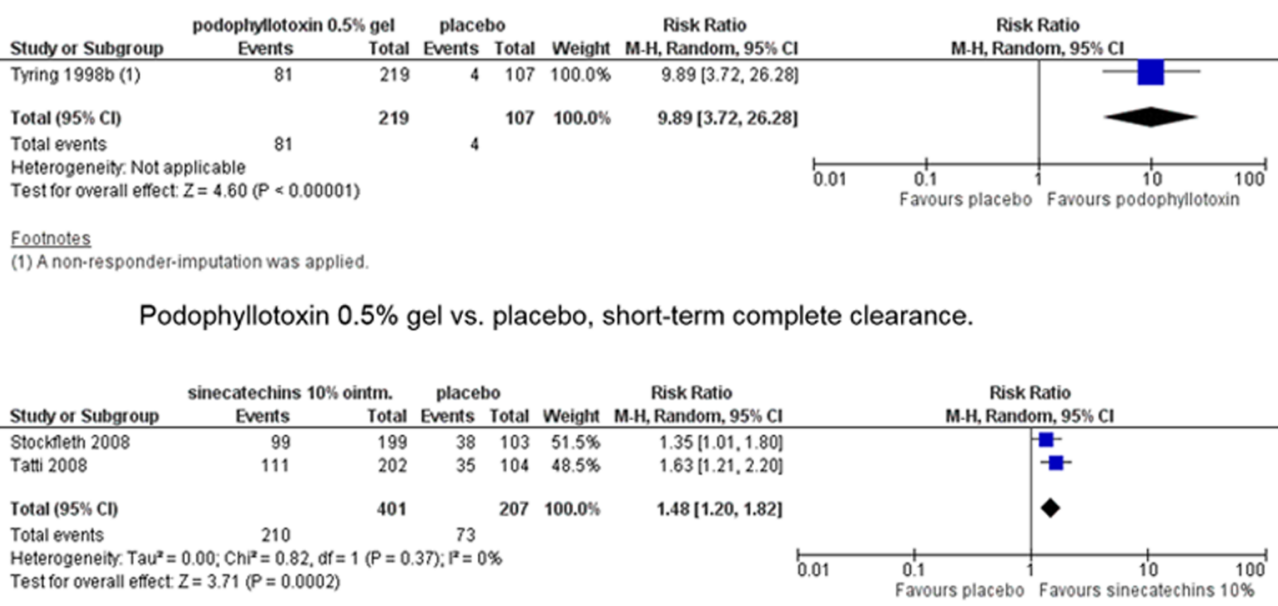

Polyphenon E (sinecatechins) 10\% ointment vs. placebo, short-term complete clearance.

$\mathrm{F}$

\begin{tabular}{|c|c|c|c|c|c|c|c|c|c|}
\hline Study or Subgroup & \multicolumn{2}{|c|}{ sinecatechins $15 \%$ ointm. } & \multicolumn{2}{|c|}{ placebo } & Weight & $\begin{array}{c}\text { Risk Ratio } \\
\text { M.H, Random, } 95 \% \mathrm{CI}\end{array}$ & \multicolumn{3}{|c|}{$\begin{array}{c}\text { Risk Ratio } \\
\text { M.H, Random, } 95 \% \mathrm{Cl}\end{array}$} \\
\hline Gross 2007 (1) & 44 & 80 & 31 & 83 & $26.7 \%$ & $1.47[1.05,2.07]$ & & & -- \\
\hline Stocklleth 2008 & 102 & 201 & 38 & 103 & $37.9 \%$ & $1.38[1.03,1.83]$ & & & - \\
\hline Tatti 2008 (2) & 111 & 196 & 35 & 104 & $35.5 \%$ & $1.68[1.25,2.26]$ & & & $\Rightarrow$ \\
\hline Total (95\% Cl) & & 477 & & 290 & $100.0 \%$ & $1.50[1.26,1.80]$ & & & $\bullet$ \\
\hline Total events & 257 & & 104 & & & & & & \\
\hline $\begin{array}{l}\text { Heterogeneity. Tauz } \\
\text { Test for overall effect }\end{array}$ & $\begin{array}{l}0.00 ; C h \mathrm{P}^{2}=0.9 \\
Z=4.54(P<0 .\end{array}$ & $(P=0$. & $62) ; P^{2}=$ & & & & 0.01 & Favours placebo & $\begin{array}{c}10 \\
100 \\
\text { Favours sinecatechins } 15 \%\end{array}$ \\
\hline
\end{tabular}

Eootnotes

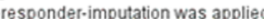

(2) A non-responder-imputation was applied

Polyphenon E (sinecatechins) 15\% ointment vs. placebo, short-term complete clearance.

Figure 3 Forest plots of short-term and intermediate-term complete clearance in placebo-controlled trials. 
A

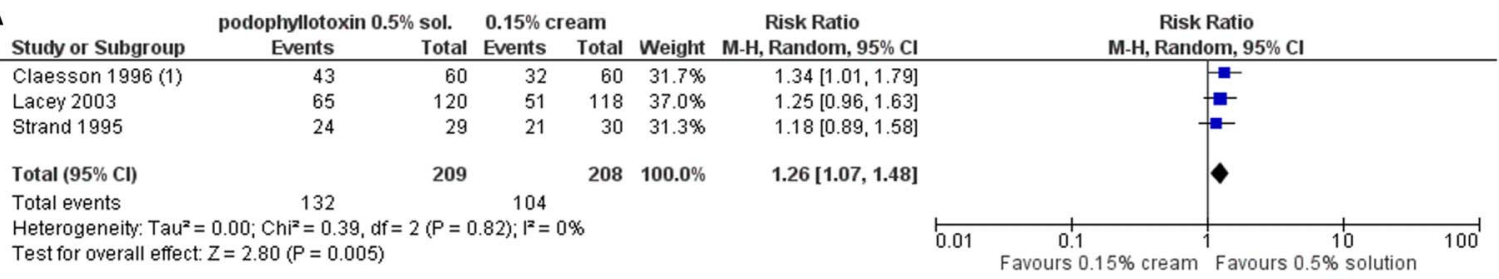

Footnotes

(1) Data solely refer to baseline lesions.

Podophyllotoxin $0.5 \%$ solution vs. podophyllotoxin $0.15 \%$ cream, short-term complete clearance.

B

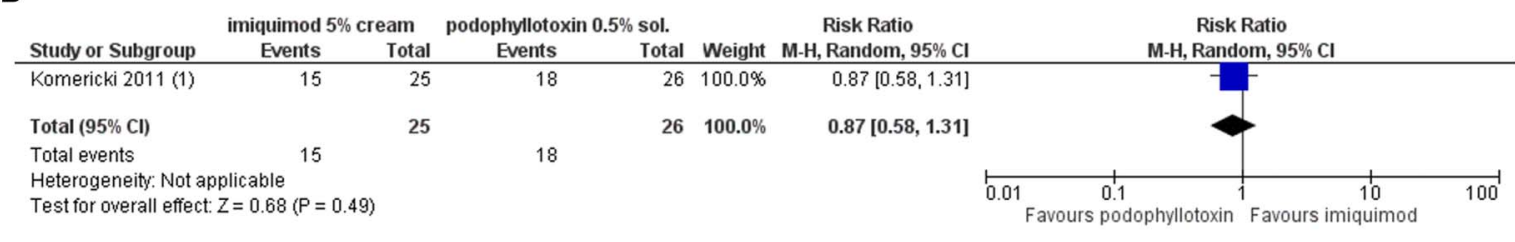

Footnotes

(1) A non-responder-imputation was applied.

Imiquimod $5 \%$ cream vs. podophyllotoxin $0.5 \%$ solution, short-term complete clearance.

C

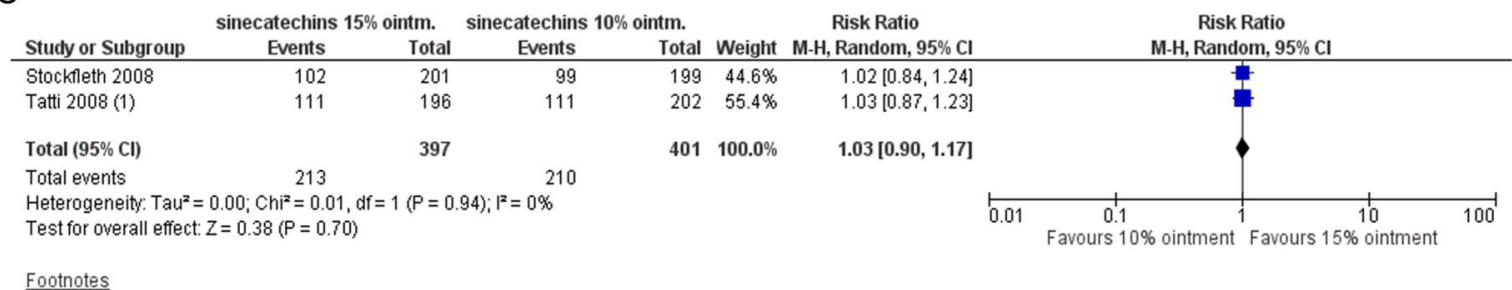

(1) A non-responder-imputation was applied.

Polyphenon E (sinecatechins) $15 \%$ vs. $10 \%$ ointment, short-term complete clearance

Figure 4 Forest plots of short-term complete clearance in active-controlled trials.

ointment is not of practical relevance due to the fact that the different concentrations are licensed in different countries.

The quality of the evidence evaluated with the GRADE approach was heterogeneous, varying from 'very low' to 'high'. The quality ratings express our confidence in the correctness of the effect estimates, and thus, the results of the meta-analyses are partially to be treated with caution. Generally, older trials were of lower methodological quality and less well reported than recent articles addressing more methodologically relevant details, according to the requirements of the CONSORT statement. ${ }^{27}$ The GRADE quality of the evidence from studies on newer preparations, such as polyphenon E, was more frequently evaluated as moderate or high.

Referring to the relative risks of CC, both podophyllotoxin $0.5 \%$ solution and imiquimod $5 \%$ cream showed the highest relative efficacy in placebo-controlled trials and were equivalent in the direct comparison. However, in the absence of direct comparisons with other interventions, no further conclusion can be drawn. Our confidence in the estimates of effect differed: it was assessed as moderate to high for interventions that had statistically significant but low relative risks for CC (imiquimod $3.75 \%$, polyphenon $\mathrm{E} 10 \%$ and $15 \%$ ointment), and low to moderate for interventions that had higher relative risks of CC when compared with placebo (podophyllotoxin $0.5 \%$ solution and gel, imiquimod 5\% cream). Furthermore, the heterogeneity of the study populations makes a comparison of relative risks difficult: The rates of CC in the placebo groups were considerably higher in polyphenon $\mathrm{E}$ trials $\left(36.9 \%,{ }^{20} 33.7 \%,{ }^{21}\right.$
$37.3 \%{ }^{22}$ ) than in trials investigating other interventions (range from $0 \%$ in four trials ${ }^{13}{ }^{16-18}$ to $14.2 \%$ in one trial ${ }^{10}$ ). This considerable difference in spontaneous clearances and the different baseline characteristics, for example, regarding number or area of AGWs (or missing data in two of the polyphenon $\mathrm{E}$ trials) indicate a limited comparability of study populations. The high rates of $\mathrm{CC}$ in the placebo groups of the polyphenon $\mathrm{E}$ trials explain the relatively low relative risk of CC for placebocontrolled polyphenon E trials, whereas the CC rates in the verum groups were comparable with those of podophyllotoxin $0.5 \%$ solution and imiquimod $5 \%$ cream.

Two publications ${ }^{10} 11$ indicate that male and female patients might exhibit different CC rates, showing CC rates of $36.6 \%$ and $18.6 \%$ in the verum groups and $14.2 \%$ and $4.2 \%$ in the placebo groups for female and male patients, respectively. Potential gender-related differences were not addressed here. The localisation of AGWs may also influence clearance rates. We could not identify data on internal AGWs. For external AGWs, the localisation was assessed during data extraction but was not sufficiently detailed in many studies. It was not possible to evaluate clearance rates of specific localisations. Further limitations to this systematic review are discussed in the online supplement.

No data on health-related QoL or other patient-reported outcomes (apart from pain) were investigated in the included trials. This is a major limitation since patient-centred outcomes should be central outcomes influencing a treatment strategy. Particularly for self-administered interventions, only well-tolerated treatment options that do not restrict health-related QoL for significant 
periods ensure a high adherence to the therapy. This is particularly important in an infectious disease that shows high rates of recurrence. However, the choice of treatment does not solely depend on the available evidence, but also on other parameters such as size, number and appearance of the lesions. Patient preferences should be considered in future.

\section{CONCLUSIONS}

Our confidence in the pooled estimates ranged from very low to high. All investigated self-administered interventions for AGWs were superior to placebo with respect to CC. To determine the relative efficacy of the different self-administered interventions, head-to-head trials are needed. Particularly regarding polyphenon $\mathrm{E}$ preparations, the absence of direct comparisons with other active compounds limits estimations of their relation to other interventions with respect to efficacy and safety. Other direct comparisons similarly require more investigation. Future research should adequately address these needs and include relevant patient-reported outcomes.

\section{Key messages}

- Anogenital warts are common STIs and may severely impact quality of life; treatment options are characterised by high rates of non-responders and recurrences.

- Relative risks of complete clearance with self-administered treatment options compared with placebo ranged from 1.48 to 19.86 (quality of the evidence: low to high).

- Few direct comparisons of interventions were available, and for methodological reasons, a ranking of the evaluated topical treatments regarding efficacy is inappropriate.

- Future research should adequately address the needs for direct comparisons of the interventions and include patient-centred outcomes such as quality of life.

\section{Handling editor Jackie A Cassell}

Contributors RNW, LW, CD and AN developed the research question and methods section. RNW and LW selected eligible studies during the title/abstract screening and full-text evaluation, extracted data from the included studies, appraised the quality of the evidence, entered and double-checked data for RevMan and analysed/interpreted the data. RNW and LW developed the draft of the review. $A N$ and $C D$ were involved in cases of dissent with respect to extracted data/ evaluations. AN and CD participated in analysing and interpreting the data and in the final editing of the draft. RNW coordinated contributions of the coauthors and compiled the final draft of the manuscript.

Funding This systematic review and meta-analysis has been supported with an unrestricted research grant by Meda Pharma GmbH \& Co. KG, Benzstrasse 1, 61352 Bad Homburg, Germany. The funding was institutional, not personal. The source of funding did not influence the conduct of the systematic review. Assessment and synthesis of the evidence were done independently from industrial interest. The sponsor had no influence on the content.

Competing interests The Division of Evidence based Medicine (dEBM) received research grants from various entities. The conduct of the current review was funded with an institutional research grant by Meda Pharma GmbH \& Co. KG as stated above. The dEBM received research grants not associated with the current work by the Paul-Ehrlich-Gesellschaft für Chemotherapie e.V., European Academy of Dermatology and Venereology, Medigene, European Dermatology Forum, Pfizer, Merz, Deutsche Dermatologische Gesellschaft, Deutsche Gesellschaft für Allergologie und klinische Immunologie, Deutsche Dermatologische Akademie and GSK. The dEBM is currently involved in the development of a German clinical practice guideline on the management of human papillomavirus-associated anogenital lesions. AN is responsible for the grants given to dEBM. RNW, LW and CD declare to have no further conflicts of interests. AN has received personal honoraria for educational activity with direct or indirect sponsoring from Novartis, Pfizer, Boehringer Ingelheim, Bayer Healthcare, Jansen, MEDA.
Provenance and peer review Not commissioned; externally peer reviewed.

Data sharing statement This was a systematic review with meta-analysis. All data items extracted from the original studies by the authors are presented within the article or its online supplement.

\section{REFERENCES}

1 Guyatt G, Oxman AD, Akl EA, et al. GRADE guidelines: 1. Introduction—GRADE evidence profiles and summary of findings tables. I Clin Epidemiol 2011;64:383-94.

2 Higgins JPT, Altman DG, Gøtzsche PC, et al. The Cochrane Collaboration's tool for assessing risk of bias in randomised trials. BMJ. 2011;343:d5928.

3 Guyatt G, Oxman AD, Sultan S, et al. GRADE guidelines: 11. Making an overall rating of confidence in effect estimates for a single outcome and for all outcomes. J Clin Epidemiol 2014;66:151-7.

4 Guyatt GH, Oxman AD, Vist G, et al. GRADE guidelines: 4. Rating the quality of evidence - study limitations (risk of bias). J Clin Epidemiol 2014;64:407-15.

5 Guyatt GH, Oxman AD, Kunz R, et al. GRADE guidelines: 7. Rating the quality of evidence - inconsistency. J Clin Epidemiol 2014;64:1294-302.

6 Guyatt GH, Oxman AD, Kunz R, et al. GRADE guidelines: 8. Rating the quality of evidence-indirectness. J Clin Epidemiol 2014;64:1303-10.

7 Guyatt GH, Oxman AD, Kunz R, et al. GRADE guidelines 6 . Rating the quality of evidence-imprecision. J Clin Epidemiol 2014;64:1283-93.

8 Guyatt GH, Oxman AD, Montori V, et al. GRADE guidelines: 5. Rating the quality of evidence—publication bias. J Clin Epidemiol 2014;64:1277-82.

9 Beutner KR, Tyring SK, Trofatter KF Jr, et al. Imiquimod, a patient-applied immune-response modifier for treatment of external genital warts. Antimicrob Agents Chemother 1998;42:789-94.

10 Baker DA, Ferris DG, Martens MG, et al. Imiquimod 3.75\% cream applied daily to treat anogenital warts: combined results from women in two randomized, placebo-controlled studies. Infect Dis Obstet Gynecol 2011;2011:806105.

11 Rosen T, Nelson A, Ault K. Imiquimod cream 2.5\% and 3.75\% applied once daily to treat external genital warts in men. Cutis 2015;96:277-82.

12 Arican 0 , Guneri $F$, Bilgic $K$, et al. Topical imiquimod $5 \%$ cream in external anogenital warts: a randomized, double-blind, placebo-controlled study. J Dermatol 2004;31:627-31

13 Beutner KR, Spruance SL, Hougham AJ, et al. Treatment of genital warts with an immune-response modifier (imiquimod). J Am Acad Dermatol 1998;38(2 Pt 1):230-9.

14 Edwards L, Ferenczy A, Eron L, et al. Self-administered topical 5\% imiquimod cream for external anogenital warts. Arch Dermatol 1998;134:25-30.

15 Tyring SK, Arany I, Stanley MA, et al. A randomized, controlled, molecular study of condylomata acuminata clearance during treatment with imiquimod. J Infect Dis 1998;178:551-5.

16 Beutner KR, Conant MA, Friedman-Kien AE, et al. Patient-applied podofilox for treatment of genital warts. Lancet 1989;1:831-4.

17 Kirby P, Dunne A, King DH, et al. Double-blind randomized clinical trial of self-administered podofilox solution versus vehicle in the treatment of genital warts. Am J Med 1990;88:465-9.

18 Krogh G, Szpak E, Andersson M, et al. Self-treatment using 0.25\%-0.50\% podophyllotoxin-ethanol solutions against penile condylomata acuminata: a placebo-controlled comparative study. Genitourin Med 1994;70:105-9

19 Tyring S, Edwards L, Cherry LK, et al. Safety and efficacy of $0.5 \%$ Podofilox gel in the treatment of anogenital warts. Arch Dermatol 1998;134:33-8.

20 Stockfleth E, Beti H, Orasan R, et al. Topical Polyphenon E in the treatment of external genital and perianal warts: a randomized controlled trial. $\mathrm{Br}$ । Dermatol 2008:158:1329-38

21 Tatti S, Swinehart JM, Thielert C, et al. Sinecatechins, a defined green tea extract, in the treatment of external anogenital warts: a randomized controlled trial. Obstet Gynecol 2008;111:1371-9.

22 Gross $\mathrm{G}$, Meyer KG, Pres $\mathrm{H}$, et al. A randomized, double-blind, four-arm parallel-group, placebo-controlled Phase II/III study to investigate the clinical efficacy of two galenic formulations of Polyphenon $E$ in the treatment of external genital warts. J Eur Acad Dermatol Venereol 2007;21:1404-12.

23 Claesson $\mathrm{U}$, Lassus A, Happonen $\mathrm{H}$, et al. Topical treatment of venereal warts: a comparative open study of podophyllotoxin cream versus solution. Int I STD AIDS 1996;7:429-34

24 Lacey CJ, Goodall RL, Tennvall GR, et al. Randomised controlled trial and economic evaluation of podophyllotoxin solution, podophyllotoxin cream, and podophyllin in the treatment of genital warts. Sex Transm Infect 2003;79:270-5.

25 Strand A, Brinkeborn RM, Siboulet A. Topical treatment of genital warts in men, an open study of podophyllotoxin cream compared with solution. Genitourin Med 1995; 71:387-90

26 Komericki P, Akkilic-Materna M, Strimitzer T, et al. Efficacy and safety of imiquimod versus podophyllotoxin in the treatment of anogenital warts. Sex Transm Dis 2011;38:216-18.

27 Begg C, Cho M, Eastwood S, et al. Improving the quality of reporting of randomized controlled trials: The consort statement. JAMA 1996;276:637-9. 